\title{
A methodological approach for sediment core dating
}

\author{
R. Ocone, M. Belli, L. Schiozzi ${ }^{1}$ and A. Fazio ${ }^{2}$ \\ ANPA, Agenzia Nazionale per la Protezione dell'Ambiente, Roma, Italy \\ ${ }^{1}$ Dip. Scienze Geologiche, Ambientali e Marine Università degli Studi di Trieste, Italy \\ ${ }^{2}$ INMRI, Istituto Nazionale Metrologia Radiazioni lonizzanti, Enea, Roma, Italy
}

\begin{abstract}
A methodological procedure to date sediment cores by gamma measure of ${ }^{210} \mathrm{~Pb}$ is proposed. This procedure includes the self-absorption correction, experimentally obtained, and the sediment core dating, by software computation. Selection of detector type, sample container and measurement configuration are discussed. In the paper measurement corrections for core slices with very low content of sediment, with respect to the volume of reference calibration source, are also discussed. The method has been validated performing a comparison with two reference materials. As conclusion, the application of the procedure to sediment core coming from Venice lagoon is showed.
\end{abstract}

\section{INTRODUCTION}

In environmental impact assessment, it is often necessary to estimate the sedimentation rates in water bodies in order to date accidental contamination events. Sedimentation rates are routinely estimated by measuring the ${ }^{210} \mathrm{~Pb}$ profiles in sediment cores. Then the CIC (Constant Initial Concentration) and the CRS (Constant Rate Supply) models have been applied. The ${ }^{210} \mathrm{~Pb}$ content in the surface sediment layers has two natural sources: ${ }^{226} \mathrm{Ra}$ from sediments and ${ }^{222} \mathrm{Rn}$ from the atmosphere. As a results often there is more ${ }^{210} \mathrm{~Pb}$ then ${ }^{226} \mathrm{Ra}$ in such material in terms of activity concentrations. Considering the half-life of ${ }^{210} \mathrm{~Pb}$ (22.2 years), the excess due to the contribution of ${ }^{222} \mathrm{Rn}$ allows to estimate the sedimentation rates and the age of the different sediment layers for time scale below 100 years.

The ${ }^{210} \mathrm{~Pb}$ activity can be measured by gamma spectrometry using the $46.52 \mathrm{kev}$ spectra line $(\mathrm{I}=4.05 \%)$.

In this paper a procedure developed at ANPA (the Italian Environmental Protection Agency) Laboratory is reported. Due to the low energy of the gamma emission, self-absorption correction factor has been applied as proposed by Cutshall et al. [1].

Different correction types such as the effects on geometry efficiencies due to low amount of sample material are applied. A full estimation of the uncertainty budget has been carried out. At last the sedimentation rates have been estimated by the CIC and CRS models using the software developed by Shukla[2]. An application to a sediment core coming from the Venice lagoon, northeastern part of Italy, is reported.

\section{MATERIALS AND METHODS}

To quantify the behaviour of self-attenuation factor versus the density of the sample several tests, on soil samples with similar mineralogical composition and different density, are preliminary carried out. In addition, to assess the chemical composition influence on self-absorption factor, tests on gel samples, with different chemical composition in comparison with soil samples, have been performed.

Sediment slices have been packed in plastic cans of $50 \mathrm{~cm}^{3}$ volume and hermetically sealed. The emission rate of $46.5 \mathrm{keV}$ gamma rays from each sample slice has been measured using an extended tange HPGe detector. Routinely energy and efficiency calibrations and background subtractions have been performed.

The self-absorption correction factor has been measured for each sample as reported by Cutshall [1] and each sample measure has been corrected by this factor. A certified reference ${ }^{210} \mathrm{~Pb}$ source has been located at $10 \mathrm{~cm}$ distance from the top of sample in order to have, with good approximation, a parallel gamma beam. The distance of $10 \mathrm{~cm}$ has been chosen after optimisation experiments for the selected source intensity. The experiment has been carried out at INMRI (Istituto Nazionale Metrologia Radiazioni Ionizzanti), ENEA-Casaccia Italy.

In the case of amount of sediment less than $50 \mathrm{~cm}^{3}$ (geometry available for efficiency calibration), an empirically correction has been applied: measures of different volume of the same sample have been
fitted to assess the necessary correction equation to be applied to have the same ${ }^{210} \mathrm{~Pb}$ activity
concentration. concentration. 


\section{RESULTS AND DISCUSSION}

The self-absorption correction factor for soil and gel samples is reported in Figure 1. As expected, this factor shows a straight dependence with density. The different trend, on samples with different chemical composition, is well established by the theory of gamma rays interaction with the matter and lies on the atomic number. The data within $(1.00-1.25) \mathrm{g} / \mathrm{cm}^{3}$, that are outside the main trend, are related to the gel samples. In the case of materials with similar chemical compositions but with different density (samples with different grain size distribution due to sieving and milling) it is possible to assess the self-absorption correction factor by fitting data obtained from samples selected from a wide range of density.

In the case of sediments dating, however, it is not possible to use the above reported fitting method, because different layers of a same core could have different chemical composition due to the different geo-chemical origin. Then the self-absorption factor has to be measured for each layer sample.

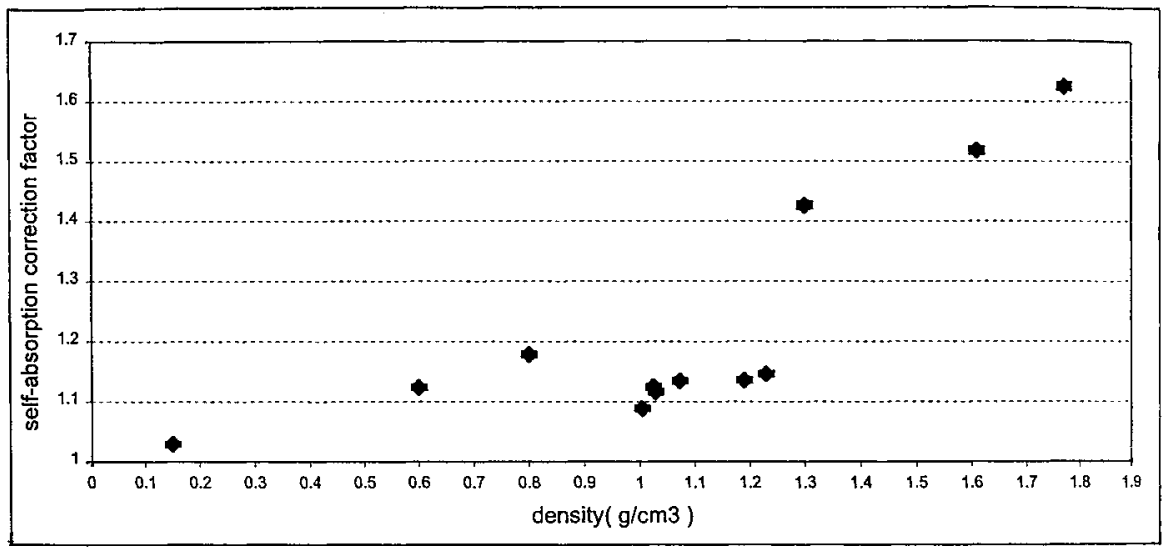

Figure 1: Self-absorption coefficient versus density.

To verify the full method, two IAEA reference materials have been used. The comparison results are reported in Table 1.

Table 1: ${ }^{210} \mathrm{~Pb}$ activity concentration measurements and corrections on two reference IAEA soil materials.

\begin{tabular}{l|l|l|l|l|l|l|}
\hline${ }^{210} \mathrm{~Pb}$ & Self-abs. & $\begin{array}{l}\mathrm{Bq} / \mathrm{kg} \\
\text { (measured) }\end{array}$ & $\begin{array}{l}\mathrm{Bq} / \mathrm{kg} \\
\text { (corrected) }\end{array}$ & $\begin{array}{l}\text { Uncertainty } \\
\text { ( Bq/kg) }\end{array}$ & $\begin{array}{l}\mathrm{Bq} / \mathrm{kg} \\
\text { (recommended) }\end{array}$ & $\begin{array}{l}\mathrm{Bq} / \mathrm{kg} \text { confidence } \\
\text { interval }(95 \%)\end{array}$ \\
\hline IAEA 326 & 1.80 & 32.0 & 57.6 & $+/-4.6$ & 53.3 & $48.8-57.8$ \\
\hline IAEA 327 & 1.75 & 35.9 & 62.8 & $+/-5.0$ & 58.8 & $53.9-63.7$ \\
\hline
\end{tabular}
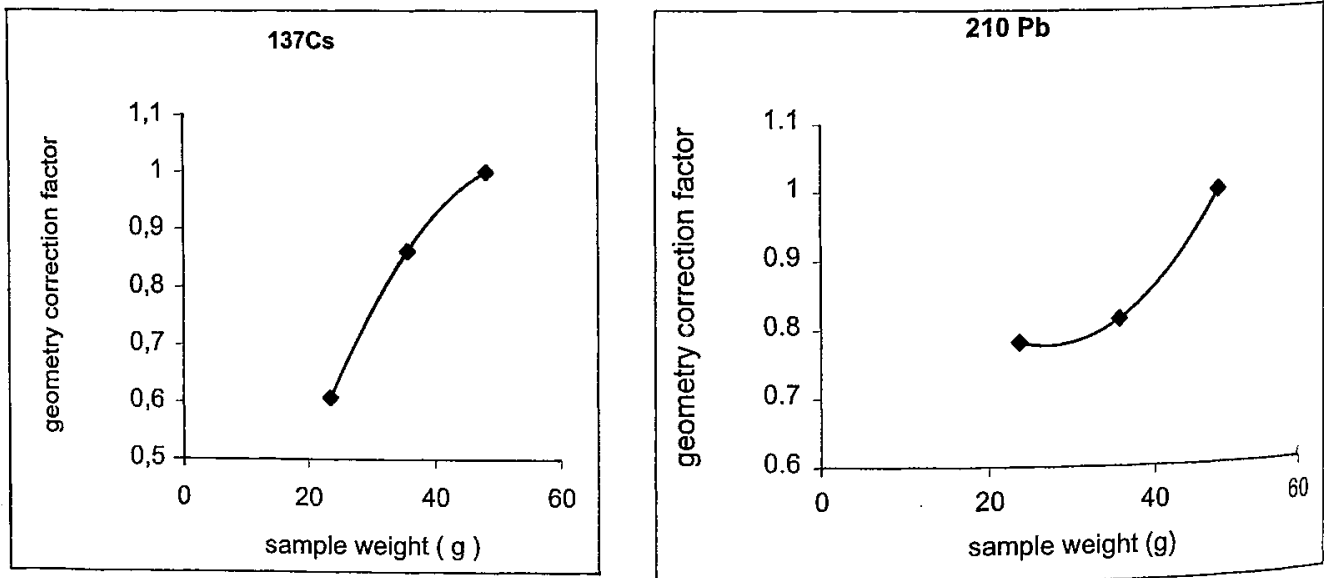

Figure 2: The geometry correction factor for low amount of sediment: a) ${ }^{137} \mathrm{Cs}$ and b) ${ }^{210} \mathrm{~Pb}$ 
The applied empirical correction factor, when the quantity of sample is not enough to reach the full measurement geometry calibration set-up, is showed in Figure 2.

Comparing a) and b) of the Figure 2, it is possible to observe an highest decrease, at low material content, for the ${ }^{210} \mathrm{~Pb}$ correction factor. This is due to two concomitance effects. First, as in the activity concentration calculation the counting rate is divided by the geometry efficiency, in case of low material content this efficiency is lower than that one suitable; the consequence is a measurement overvaluing. Second, for low material amount, the self-absorption correction factor, initially applied to a highest volume, is overestimated and allows a measurement overvaluing too. The budget of uncertainties for the full procedure takes in account the propagation the uncertainties of all the parameter used, including porosity and density used in the CIC and CRS models. Figures 3 and 4 report ${ }^{210} \mathrm{~Pb}$ and ${ }^{137} \mathrm{Cs}$ activity concentrations measured in a sediment core collected in the Venice lagoon.

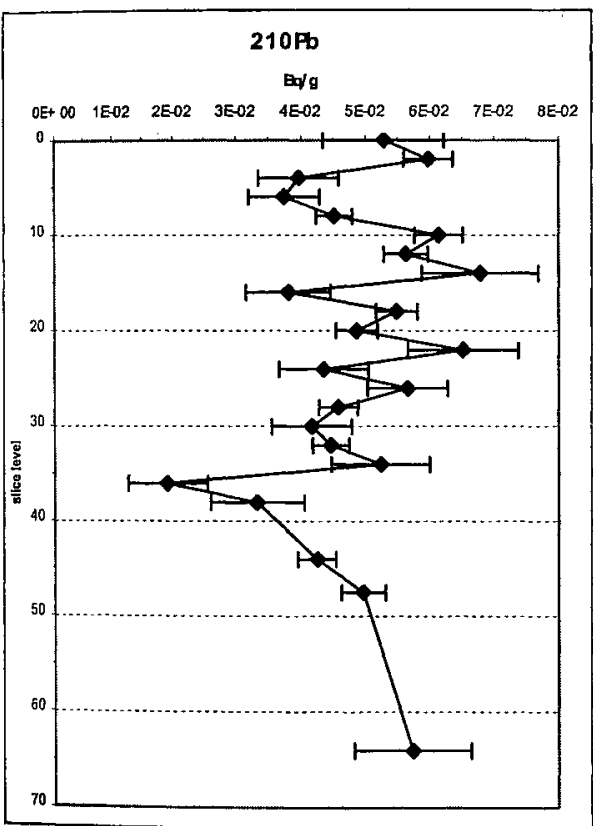

Figure $3:{ }^{210} \mathrm{~Pb}$ activity concentration versus slice level Figure 4: ${ }^{137} \mathrm{Cs}$ activity concentration versus slice level

Figure 3 reports the lead sediment profile in the first $64 \mathrm{~cm}$ of the sediment core. The ${ }^{210} \mathrm{~Pb}$ behaviour shows irregular distribution. There are several relative maximum. To explain the behaviour of ${ }^{210} \mathrm{~Pb}$ profile, the ${ }^{137} \mathrm{Cs}$ distribution along the sediment core has been measured (Figure 4). The trend appears more regular if compared to the ${ }^{210} \mathrm{~Pb}$ profile and indicates that there is no mixing effect along the vertical distribution. The behaviour of the ${ }^{137} \mathrm{Cs}$ shows two different peaks at $3 \mathrm{~cm}$ and $23 \mathrm{~cm}$ depth. The activity concentration and its location at the $3 \mathrm{~cm}$ depth peak refer to deposition of the Chernobyl accident. The $23 \mathrm{~cm}$ depth peak could be attributable to the nuclear weapon tests of the sixties, also considering the lower activity concentrations found in the layer. 
In Figure 5 the profile of ${ }^{214} \mathrm{Bi}$ shows a different distribution of activity concentration compared to ${ }^{210} \mathrm{~Pb}$.

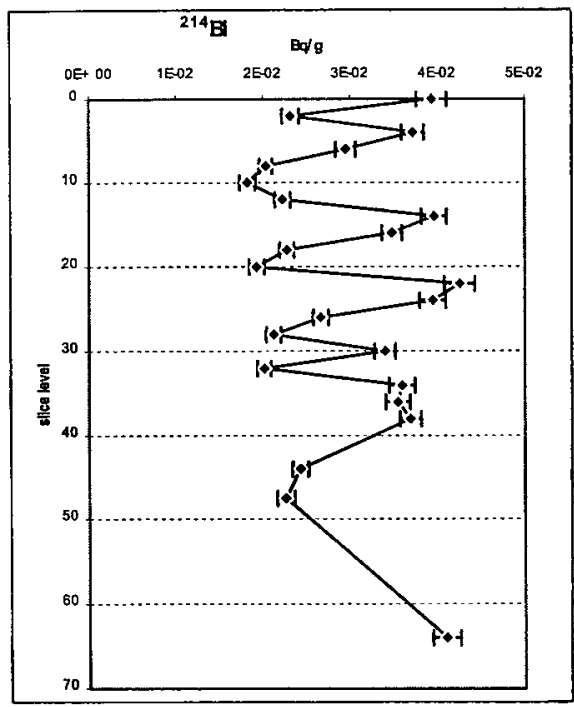

Figure 5: ${ }^{214} \mathrm{Bi}$ activity concentration versus slice level

Due to its short half-life, ${ }^{214} \mathrm{Bi}$ is essentially due to ${ }^{226} \mathrm{Ra}$ directly originated in the sediment.

The irregular behaviour of ${ }^{214} \mathrm{Bi}$ profile is attributable to the different composition of the different sediment layers. On this basis, it is possible to argue that the shift from the ${ }^{214} \mathrm{Bi}$ of the ${ }^{210} \mathrm{~Pb}$ profile is due to ${ }^{210} \mathrm{~Pb}$ from anthropogenic origin: the atmospheric depositions and the erosion of phosphogypsum deposited on the border of the Venice lagoon [3]. The increase found in the last layer for ${ }^{210} \mathrm{~Pb}$ and ${ }^{214} \mathrm{Bi}$ is attributable to the geo-chemical origin of the sediment.

To assess the unsupported ${ }^{210} \mathrm{~Pb}$ profile, showed in Figure 6 , the ${ }^{210} \mathrm{~Pb}$ activity concentration derived from the $(165-166) \mathrm{cm}$ layer has been used. This choice derives from the results of a previously radiocarbon dating study that evaluate for this layer an age of $3790 \pm 30$ y [4].

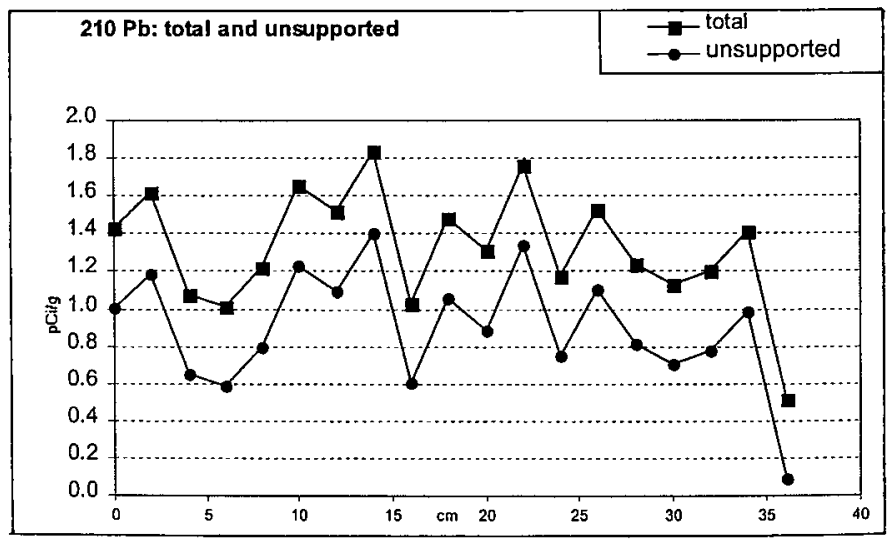

Figure 6: total and unsupported ${ }^{210} \mathrm{~Pb}$ activity concentration versus depth

To date the different sediment layers of the profile, the Shukla code [2] based on the constant incoming concentration (CIC) and on constant rate of supply (CRS) has been applied. Appleby and Kirnichny 1990 [5] suggest to use CRS model in the case of not monotone distribution of ${ }^{20} \mathrm{~Pb}$ but with a wellmarked ${ }^{137} \mathrm{Cs}$ peaks due to Chernobyl and nuclear weapon tests depositions. For this reason the profile has been divided in three intervals: $(0-8) \mathrm{cm},(10-18) \mathrm{cm},(20-38) \mathrm{cm}$. Results and uncertainties are reported in Table 2 and showed in Figure 7 . The $3 \mathrm{~cm}$ and the $23 \mathrm{~cm}$ layer are respectively dated at 1988 and 
1954. This result is in good agreement with the above reported discussion on ${ }^{137} \mathrm{Cs}$ at this depth of the sediment profile.

Table 2: CRS age calculation results of core slices

\begin{tabular}{|cccc|}
\hline $\begin{array}{c}\text { mean } \\
\text { depht (cm) }\end{array}$ & $\begin{array}{c}\text { CRS age } \\
\text { (years) }\end{array}$ & date & $\begin{array}{c}\text { uncertainties } \\
\text { (years +/-) }\end{array}$ \\
\hline 1 & 2.7 & 1996 & 1.4 \\
3 & 10.9 & 1988 & 2.5 \\
5 & 21.5 & 1977 & 7.9 \\
7 & 31.8 & 1967 & 11.0 \\
9 & 32.3 & 1967 & 6.0 \\
11 & 33.7 & 1965 & 5.8 \\
13 & 35.4 & 1964 & 6.1 \\
15 & 37.3 & 1962 & 9.7 \\
17 & 39.0 & 1960 & 14.5 \\
19 & 40.9 & 1958 & 5.3 \\
21 & 44.7 & 1954 & 6.4 \\
23 & 49.6 & 1949 & 11.0 \\
25 & 60.2 & 1939 & 17.5 \\
27 & 60.2 & 1939 & 11.9 \\
29 & 66.7 & 1932 & 9.4 \\
31 & 73.2 & 1926 & 20.3 \\
33 & 81.8 & 1917 & 11.5 \\
35 & 99.9 & 1899 & 25.7 \\
37 & 122.6 & 1876 & 31.5 \\
\hline
\end{tabular}

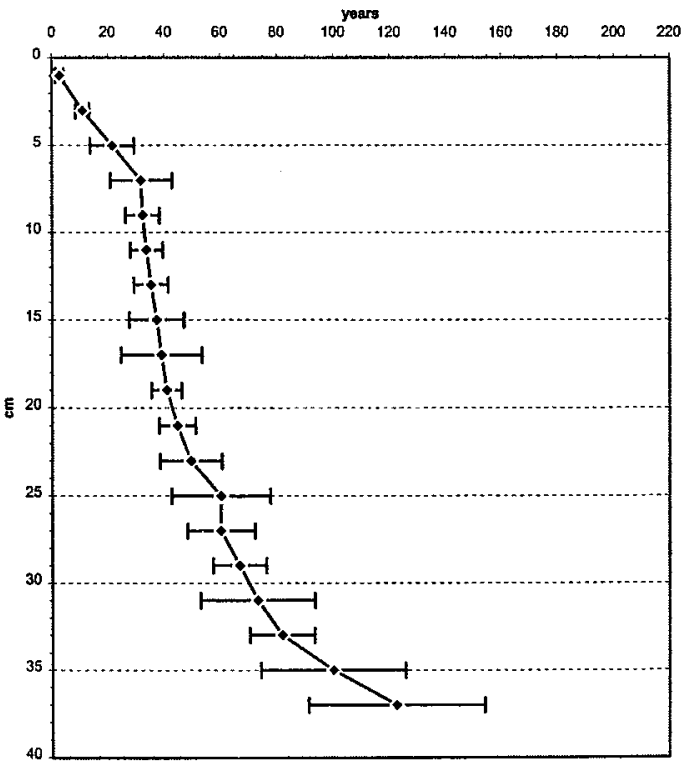

Figure 7: age versus depth. 


\section{CONCLUSIONS}

The method of ${ }^{210} \mathrm{~Pb}$ measurement above reported is more simply and faster than the radiochemical method, because it is not necessary to wait the in growth of ${ }^{210} \mathrm{Bi}$ for 40 days.

To determine the value of supported ${ }^{210} \mathrm{~Pb}$ in each layer of sediment an improvement could be reached by sealing the measurement cans and waiting for the equilibrium of ${ }^{226} \mathrm{Ra}$ and its daughters. This equilibrium is reached at $90 \%$ in about 20 days after sealing considering the ${ }^{222} \mathrm{Rn}$ half-life $(3.82 \mathrm{~d})$. In this case the ${ }^{226} \mathrm{Ra}$ activity concentration give the value of supported ${ }^{210} \mathrm{~Pb}$.

\section{Acknowledgments}

The authors are grateful to Dr. P De Felice (INMRI-ENEA Casaccia, Rome) and Dr. U. Sansone (ANPA, Rome) for useful discussions and suggestions.

\section{References}

[1] Cutshall H., et al., Nuclear Instruments and Methods 206 (1983) 309-312.

[2] Shukla B.S., 210Pb dating of Sediments (software and user guide) (Environmental Reserch \& publications INC 1997) Hamilton, Ontario, Canada.

[3] Belli M.et al., "Le discariche di fosfogessi nella laguna di Venezia: valutazioni preliminari dell'impatto radiologico ", ANPA, Serie stato dell'Ambiente 8/2000.

[4] Schiozzi L., "Utilizzo dei sedimenti come mezzo di monitoraggio ambientale", Post Doctoral Thesis on 'Scienze Ambientali' (Scienze del Mare), University of Trieste, 1998-2001.

[5] Appleby P.G. \& Kirnichny V., Report on the Radiometric Dating of Three Sediment Cores From the Dnieper River and its Estuary, 1990. 